\title{
Trends in agri-food choices for health since the 1960s: the case of fatty acids
}

\author{
Michel Duru* \\ UMR AGIR, INRA, Université de Toulouse, INPT, 31324 Castanet-Tolosan, France
}

Received 16 April 2019 - Accepted 27 September 2019

\begin{abstract}
The FA composition of our diet affects human health: SFAs and n-6 PUFAs in excess are a risk factor for a number of chronic diseases, while n-3 PUFAs have a protective role. These FAs should be considered together, since an excessively high $n-6: n-3$ ratio is linked to a strong pro-inflammatory effect. We reconstructed the FA composition of the French diet from the 1960s to the present to identify the main reasons for decreases or increases due to agriculture, food processing or food choices. From the $1960 \mathrm{~s}$ to the late 1990s, the diet increased in SFA and n-6 PUFA levels and likely decreased in n-3 PUFA level. Consequently, food behaviors did not follow dietary recommendations. For SFAs, this was due to the sharp increase in cheese and, to a smaller extent, palm oil consumption. For n-6 PUFAs, it was due to the sharp increase in oil consumption, especially linoleic sunflower oil. For n-3 PUFAs, this was due mainly to replacement of grass by maize and soybean meal to feed ruminants. This trend has reversed since the 2000s: the SFA level decreased due to decreased consumption of palm oil and genetic improvements in pigs and poultry, n-6 PUFA level decreased due to increased consumption of oleic instead of linoleic sunflower oil, and n-3 PUFA level increased due to increased consumption of rapeseed oil. These changes are consistent with the FA composition observed in breast milk. Despite these improvements, however, the average dietary composition remains far from the recommendations, especially for n-3 PUFAs. We show the potential for improvement by supplementing animal feed with flaxseed and increasing consumption of oleic sunflower and rapeseed oils, at the expense of that of other oils.
\end{abstract}

Keywords: dairy products / diet / feed / meat / oil / polyunsaturated fatty acids / saturated fatty acids

Résumé - Évolution des choix agroalimentaires pour la santé depuis les années 1960 : le cas des acides gras. La composition de notre alimentation en acides gras (AG) affecte notre santé : les acides gras saturés (AGS) et les acides gras polyinsaturés (AGPI) $n-6$ en excès sont un facteur de risque pour de nombreuses maladies chroniques, tandis que les AGPI n-3 ont un rôle protecteur. Ces AG doivent être considérés ensemble, car une valeur excessive du rapport n-6/n-3 a un puissant effet pro-inflammatoire. Nous avons reconstitué la composition du régime alimentaire français en AG depuis les années 1960 afin d'identifier les principales raisons des baisses ou des augmentations dues à l'agriculture, à la transformation des aliments ou aux choix alimentaires. Entre les années 1960 et la fin des années 1990, la composition de notre assiette a augmenté en AGS et AGPI n-6 et a probablement diminué en AGPI n-3. En conséquence, les comportements alimentaires n'ont pas suivi les recommandations diététiques. Cela est dû : (i) pour les AGS, à la forte augmentation de la consommation de fromage et dans une moindre mesure d'huile de palme ; (ii) pour les AGPI n-6, à la forte augmentation de la consommation d'huiles, en particulier l'huile de tournesol linoléique ; (iii) pour les AGPI n-3, à la moindre place de l'herbe au profit du maïs et du tourteau de soja dans l'alimentation des ruminants. Ces tendances se sont inversées depuis les années 2000 : (i) diminution de la consommation d'AGS en raison de la diminution de la consommation d'huile de palme et des améliorations génétiques pour le porc et la volaille; (ii) diminution de notre consommation en AGPI n-6 en raison de la consommation accrue d'huile de tournesol oléique au détriment de l'huile de tournesol linoléique; (iii) augmentation de la consommation d'AGPI n-3 en raison de la consommation accrue d'huile de colza. Ces

\footnotetext{
Contribution to the Topical Issue "Lipids and health / Lipides et

santé"

*Correspondence: michel.duru@inra.fr
} 
évolutions sont cohérentes avec celles observées pour la composition en AGPI du lait maternel. Malgré ces améliorations, la composition de notre alimentation reste en moyenne éloignée des recommandations, en particulier pour les AGPI n-3. Nous montrons cependant qu'il y a un potentiel d'amélioration important en complétant l'alimentation des animaux, en particulier celle des monogastriques, avec des graines de lin, et en augmentant encore la consommation d'huiles de tournesol oléique et de colza, au détriment des autres huiles.

Mots clés : acides gras polyinsaturés / acides gras saturés / alimentation humaine / produits laitiers / régime alimentaire / viande

\section{Introduction}

The impacts of saturated fatty acids (SFAs) from agriculture and food processing on human health have long been highly publicized. Less attention has focused on polyunsaturated fatty acids (PUFAs), whose inputs and balances are influenced greatly by feeding practices of farm animals, fats used by the food industry and oils used by consumers. Many authors focus on public health issues related to the great changes in the fatty acid (FA) profile of the Western diet that have resulted from progressive changes in agricultural practices, industrial processes and consumption trends since the mid-20th century.

Recommendations about fat consumption have changed in recent decades (Legrand, 2013). A growing international consensus exists for upper limits of SFA intake, minimum attainable n-3 PUFA intake and a balance between n- 6 and n-3 PUFA intake $($ ratio $<5)$, especially when an n-3 PUFA deficiency exists (Anses, 2011). Intake of these FAs from the 1960s to 2000s has been estimated based on the main primary sources of FAs consumed (oils and animal products), which contain more n-6 PUFAs and less n-3 PUFAs than recommended (Ailhaud et al., 2006). The deviation between intake and recommendations increased during this period (Simopoulos, 2007; Molendi-Coste et al., 2011), which resulted in the implementation of public policies. Launched in 2001, the French National Health Nutrition Program (PNNS) is a public health plan established to improve the health of the French population by focusing on nutrition, recognized as one of the major determinants of human health. The 2001-2005 PNNS suggested limiting the average contribution of total FAs to less than $35 \%$ of daily energy intake, with a $25 \%$ reduction in SFA intake. In 2011, the French Agency for Food, Environmental and Occupational Health \& Safety (ANSES) updated the recommended dietary intakes of FAs, especially SFAs.

ANSES modified the recommendations significantly in 2017. For FAs, they focused in particular on the benefits of consuming vegetable oils rich in alpha-linolenic acid (ALA), an n-3 PUFA, such as rapeseed and nut oils. The recommendations also emphasized the need to reduce consumption of deli meat $(e$. $g$. ham, salami, sausage, pâté) greatly, to no more than $25 \mathrm{~g} /$ day, and to consume no more than $500 \mathrm{~g}$ of meat (e.g. beef, pork, lamb, but not poultry) per week. This reaffirmed the benefits of twice-weekly consumption of fish, including fatty fish such as sardines and mackerel ${ }^{1}$. These recommendations are consistent with epidemiological studies that show the benefits of a Mediterranean-style diet, which is characterized by relatively

\footnotetext{
${ }^{1}$ https://www.santepubliquefrance.fr/content/download/35744/ 683783.
}

high fat intake (40-50\% of total daily calories), of which SFA comprises $\leq 8 \%$ and monounsaturated FAs, mainly from olive oil, comprise $15-25 \%$ of calories. The diet is characterized by high n-3 PUFA intake from plant sources and fish, and a low n-6: n-3 PUFA ratio of 2:1-1:1 (Casas, 2014).

Analyzing impacts on health is complex and has evolved in recent decades. The main health effects of FAs studied have been cardiovascular diseases, first due to SFAs but more recently due to PUFAs and monounsaturated FAs. These FAs, among others, regulate energy and cholesterol metabolism (Hammad et al., 2015; Silva Figueiredo et al., 2017). Currently, it is well established that an excessively high n-6:n-3 ratio is linked to a strong pro-inflammatory effect, leading to low-grade inflammatory diseases (Sanders, 2014). The most recent studies examined changes in the diversity and functioning of gut microbiota to consider the complex effects of FAs through oxidative and inflammatory processes induced by these changes (Rocha et al., 2016). The composition of fat in the diet influences the functions of gut microbiota and the intestinal barrier greatly. Excess SFAs, especially palmitic acid and n-6 PUFAs, increase the risk of dysbiosis and inflammation. Conversely, n-3 PUFAs prevent n-6 dysbiosis and reduce the risk of inflammation (Alcock and Lin, 2015). Moreover, the $n-6: n-3$ PUFA ratio determines the quantity of arachidonic acid available within adipose tissue, which stimulates fat cell differentiation (Pisani et al., 2015), leading to obesity (Simopoulos, 2016). Diets rich in SFAs can promote the growth of potential pathogens (gram-negative bacteria and derived lipopolysaccharides) that have inflammatory effects by generating cytotoxic compounds (Sanz et al., 2015). It is now evident that FAs, either directly or via their metabolites, act through a wide variety of signaling pathways to influence many metabolic, inflammatory and other biological processes that influence the risk and progression of several chronic diseases, such as cardiovascular disease, obesity, cancer and arthritis. An important mechanism of FA sensing is the stimulation or inhibition of DNA transcription (Georgiadi and Kersten, 2012). A Mediterranean-style diet tends to decrease these risks through its influence on gut microbiota diversity (Del Chierico et al., 2014).

Since FAs interact, sometimes with opposite effects (SFAs vs. n-3 PUFAs), with threshold effects for n-6 PUFAs via their influence on intestinal microbiota (Xiang et al., 2019), metabolic inflammation and hepatic metabolism (Pereira de Castro et al., 2017), it is necessary to consider them together to determine their composition in the diet. This composition can change due to changes in quantities of FA sources (e.g. animal products, oils) or due to changes in the FA composition of these sources resulting from agricultural practices, especially for animal products. The health impacts of animal products depend on their FA compositions (Barendse, 2014). 
Our objective was to assess changes in FA consumption over the long term to identify what major changes in agriculture, agri-food systems and food processing explained the dynamics observed. The originality of our study lies in the identification of agricultural, processing and consumption practices that generated changes in FA consumption trends. We chose areas of progress in each of these three domains according to their intended impact and then examined them. Finally, we examined whether changes in FA consumption coincided with the nutrition transition.

\section{Materials and methods}

To estimate changes in the FA composition of the French diet, we compiled and compared a variety of available data sources. For dietary composition, the most recent estimates came from the French Individual and National Study on Food Consumption (INCA), conducted in 1997 (INCA 1), 2006-7 (INCA 2) and 2017 (INCA 3). The CIQUAL database (Ciqual, 2013) was used to obtain the FA composition of products in the diet. Consumption of FAs has been estimated only since INCA 2.

Estimates over a longer period (e.g. since 1960) were based on estimates of the quantities of raw products supplied and their FA content. To characterize trends in FA consumption, we compared several studies based on raw products supplied but which differed in FA content of the foods. For the FA composition of products in European countries, the FAO used a USDA database, since the FA composition of animal products remained constant during its study period (Schmidhuber, 2007). In contrast, Ailhaud et al. (2006) compiled results from multiple sources that considered changes in the FA composition of animal products (especially ruminants) (hereafter "Ailhaud, corrected") or that did not. In both cases, this represented "apparent" consumption, since non-consumable or wasted portions of products were not always included. Based on available literature, Duru and Magrini (2017) estimated that the non-consumable percentage was $10-25 \%$ for oils and $25-$ $35 \%$ for meats, and that the wasted percentage was $5-10 \%$. However, for these estimates to be consistent with the results of the INCA 2 study, it was necessary to assume that only $80 \%$ of the products was ultimately consumed. Therefore, differences between the two methods can approach 50\% if losses and waste are not included (Duru and Magrini, 2017). We expressed results as "apparent" consumption to indicate that losses and waste were not considered. A third method focused on the FA composition of breast milk, using some corrections to connect diet to the n-3 and n-6 PUFA contents of the milk (Guesnet et al., 2009); however, these data were available only for a few years.

To identify major changes that may have influenced composition of the French diet, we first compared the main sources of FAs according to their SFA and PUFA contents. Changes in agriculture affect the composition of animal products, while changes in food processing and food choices affect the quantity and nature of the oils used, whether consumed directly or incorporated in processed foods. For the prospective dimension of our study (Sect. 3.3), one option was to improve the PUFA composition of animal products through animal rations. For example the Bleu-Blanc-Cœur ${ }^{\circledR}$ (BBC) brand guarantees a minimum n-3 PUFA content of animal food products by establishing specifications for feeding practices ${ }^{2}$. The practices are based on feeds (e.g. grass, alfalfa, flaxseed) with a high ALA content. Such changes in feeding practices have resulted in the marketing of animal products with a better FA composition than that from conventional production and that comply with nutritional recommendations, such as increased n-3 PUFAs, a decreased n-6:n-3 PUFA ratio and decreased SFAs (e.g. Kouba and Mourot, 2011). This FA composition varies greatly depending on the cut of meat or type of deli meat considered; therefore, we chose the database of the BBC association (Schmitt et al., 2018) to obtain analysis for the same cuts of meat or dairy products from animals fed conventional rations or $\mathrm{BBC}$ rations. The $\mathrm{BBC}$ database was chosen instead of the CIQUAL database because the latter does not contain animal products derived from animals fed flaxseedsupplemented feed.

We then collected data on estimates of daily FAs consumption to analyze the major trends over the past 50 years: Schmidhuber (2007) and Ailhaud et al. (2006) from the 1960s to 2000s, INCA 2 (2006) and INCA 3 (2012). Finally, to determine the most important factors, changes in apparent consumption of the FAs were interpreted from (i) changes in agriculture, especially ruminant production (quantities of feed concentrates used, types of roughage and raw products, and estimated changes in consumption of milk, dairy products and meat), and (ii) processing and food choices (quantities of animal products and oils consumed). Based on these findings, we identified the most promising avenues in agriculture and in consumption choices to meet the average dietary recommendations and then estimated their effects.

\section{Results and discussion}

\subsection{Fatty acid composition of raw agricultural products}

For animal products, SFA contents are highest for butter and cheese, followed by deli meat. Meats have lower SFA contents (Fig. 1a). Contents of n-6 PUFAs are highest for deli meats and lowest for beef and cheese (Fig. 1b). Beef has fewer extreme values for FA content, unlike cuts of pork and poultry, since chicken thighs, for example, contain more SFA than white meat does (Figs. 1a and 1b). Mean n-3 PUFA content is highest in cheese and butter (Fig. 1b). For cuts of pork and poultry, n-6 PUFA and n-3 PUFA contents are positively correlated (n-6:n-3 PUFA ratio $=11-14$ in pork, 8-10 in chicken and rabbit, and 3-4 in beef). The n-6:n-3 PUFA ratio is highest (ca. 10) in deli meats, pork and poultry, while it is $<5$ in products derived from cattle; the latter are therefore "balanced" according to the recommendations (i.e. ratio $<5$ ) (Fig. 1b). Given the relations between the FAs, sausage, cheese and butter should be a major focus for changes in consumption.

Among n-3 and n-6 PUFAs, oils contain only ALA and linoleic acid (LA), respectively. Among oils, palm oil contains much more SFAs $(50 \%)$ than all other oils $(<15 \%)$. Analyzing LA and ALA contents (Fig. 1c), peanut, oleic sunflower and olive oils have similar compositions: little LA and almost no

\footnotetext{
${ }^{2}$ These practices convey other advantages, such as better animal health and decreased greenhouse gas emissions.
} 
(a)

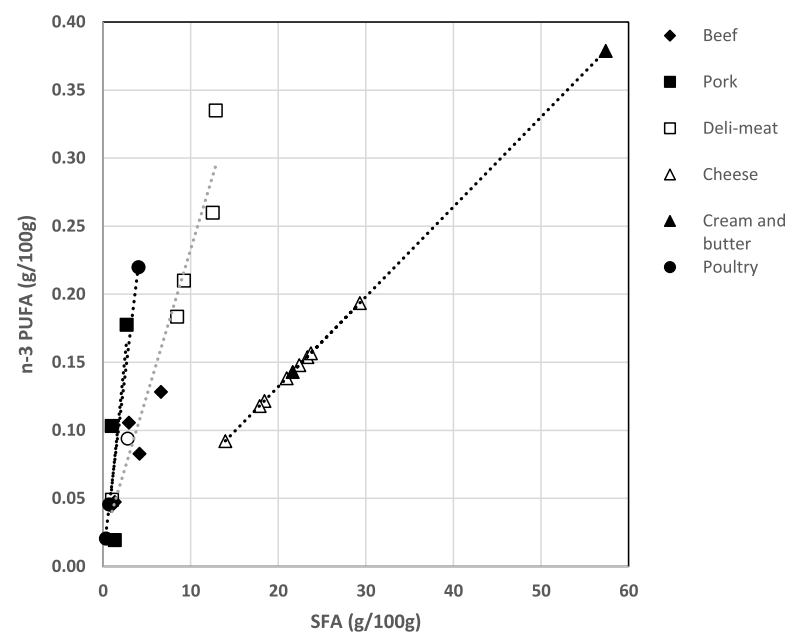

(c) (b)

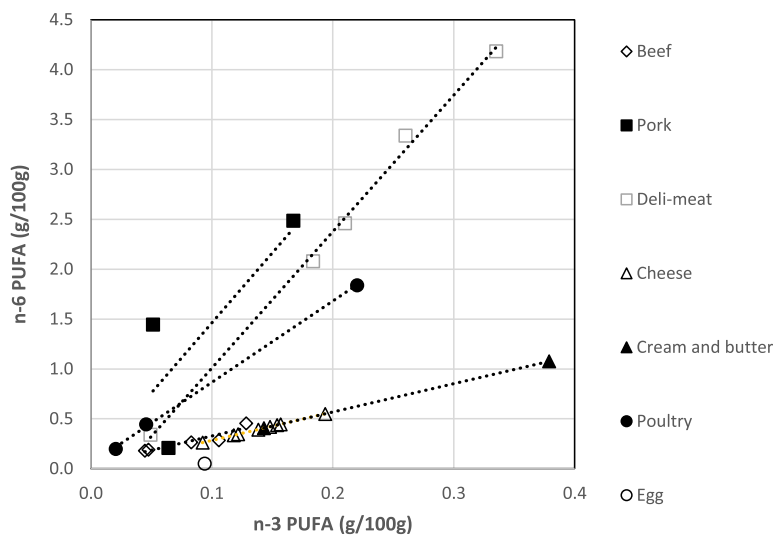

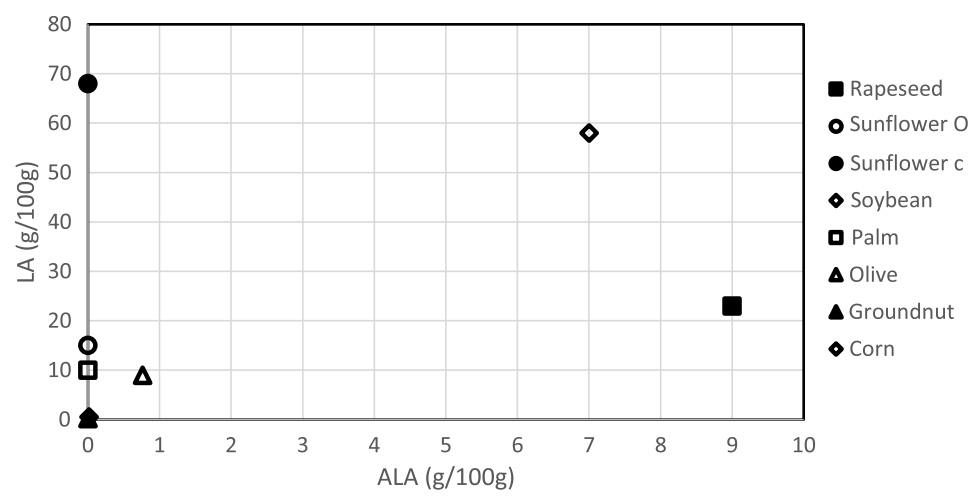

Fig. 1. a: relationship between n-3 PUFA and SFA for a range of foods and animal products (points of a same symbol represent a range of products or a given food group). Products with different symbols are listed below (from Schmitt et al., 2018): beef: beef ground 15\% fat, roast beef (topside), beef chuck; beef steak grilled (chuck); pork: rib steak, pork chop, spare ribs, pork loin (Longissimus dorsi); poultry: chicken leg, chicken breast and rabbit; deli meat: lardons, ham cooked quality label, pâté country style, dry sausage, sausage (average); cheese: camembert $20 \%$ fat, emmental cheese, grated Gruyere, cheese goat, cheese, Roquefort ewe, cheese Tomme, uncured cheese spread $42 \%$ fat, Comté cheese; b: relationship between n-6 PUFA and n-3 PUFA for a range of foods and animal products (see legends on Fig. 1a); c: relationship between LA and ALA for a range of vegetable oils. Sunflower O for oleic; sunflower c for linolenic; LA and ALA are respectively $15.5 \mathrm{and} 56 \mathrm{~g} / 100 \mathrm{~g}$ for linseed oil.

ALA. Linoleic sunflower and maize oils contain more than $50 \%$ LA, and rapeseed has 9\% ALA; soybean oil is rich in LA $(58 \%)$ and ALA (7\%). These differences suggest the need to differentiate in detail the types of oils consumed.

\subsection{Changes in the fatty acid composition of the French diet}

\subsubsection{Saturated fatty acids}

From 1961-2002, data compiled by Schmidhuber (2007) as well as by Ailhaud et al. (2006) show a consistent increase in SFA level in the diet. Both INCA studies show much lower levels, and a decrease was observed between their dates (2006 and 2012) (Fig. 2a).

\subsubsection{Polyunsaturated fatty acids}

From 1960-2002, the level of n-6 PUFA increased much faster than that of n-3 PUFAs (Fig. 2b); consequently, the n-6: n-3 PUFA ratio increased sharply (Fig. 2c). During this period, changes in n-3 PUFA intake increased or decreased depending on the method used (Fig. 2d). Estimates based on FAO statistics show an increase, while those of "Ailhaud, corrected" indicate a decrease. Since 2000, n-6 PUFA intake has decreased and n-3 PUFA intake increased for the INCA studies, breast milk composition, and Duru and Magrini (2017) estimates, resulting in a decreased n-6:n-3 PUFA ratio. Around the mid-2000s, a substantial gap was observed for the n-6 PUFA level (Fig. 2b, y-axis), likely due to differences in methods. The indirect method, which does not include losses and waste, indicated higher values for them. For the trend in the n-3 PUFA level, the observed differences among methods were consistent with those of Blasbalg et al. (2011), who showed the influence of dietary changes of animals in the United States on the n-3 PUFA content of their feeds and the subsequent decrease in the n-3 PUFA level in the human diet.

These results, although from different sources and methods, show an increase in SFA and n-6 PUFA levels, 
(a)

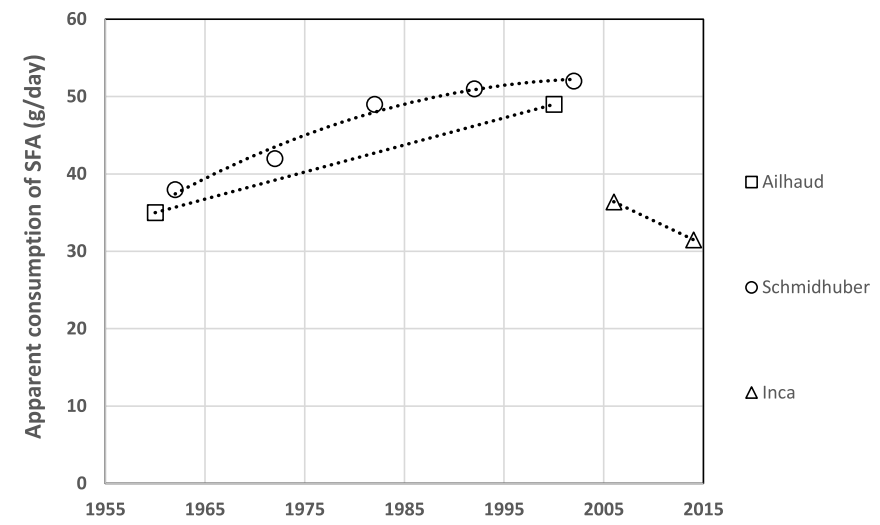

(c)

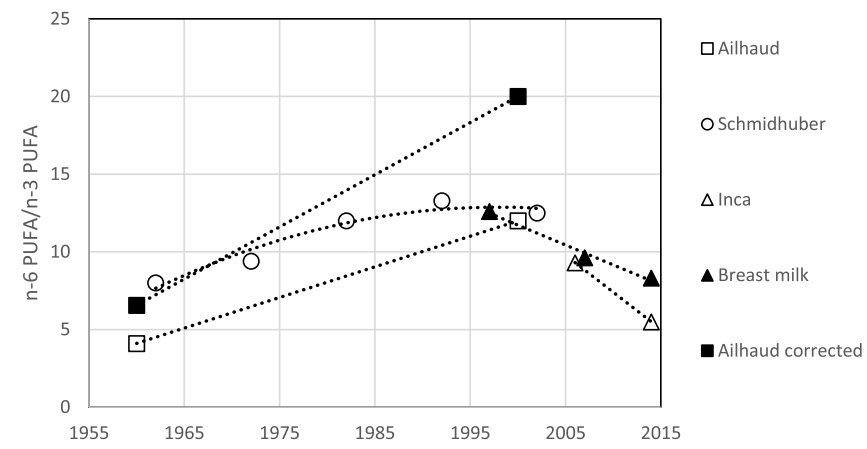

(b)

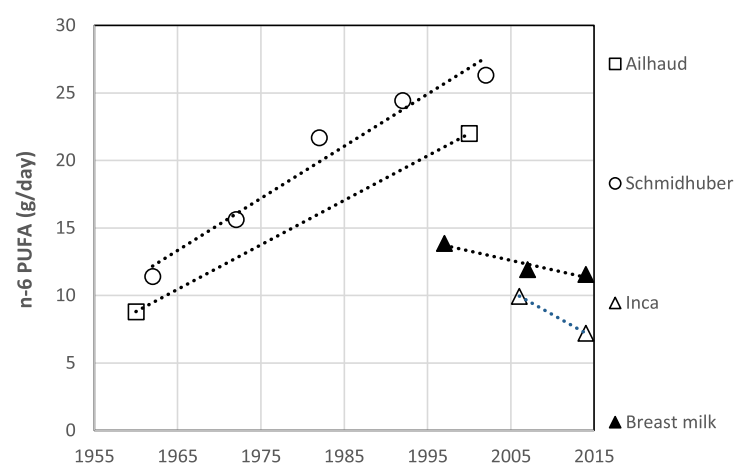

(d)

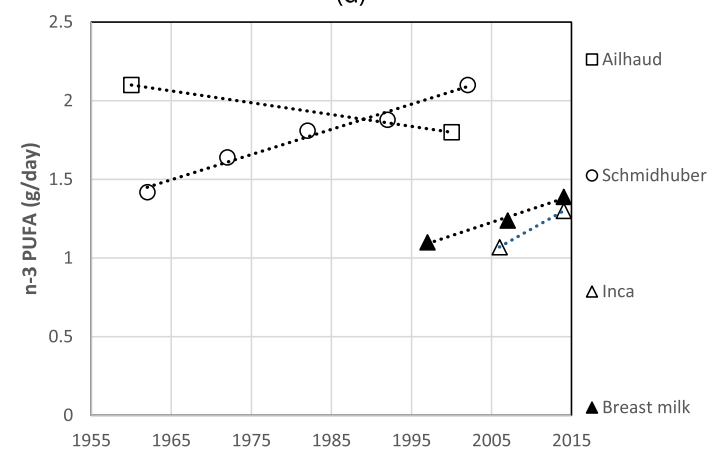

Fig 2. a: trends in apparent daily consumption of SFA (g/day) per capita in France: indirect (food supply: Ailhaud and Schmidhuber) and direct (dietary food intake $\times$ composition: Inca) methods; b: trends of apparent daily consumption of n-6 PUFA per capita in France: indirect (food supply: Ailhaud and Schmidhuber) and direct (dietary food intake $\times$ composition: Inca) methods, and composition of breast milk (Couëdelo et al., 2014); c: trends of n-6 PUFA/n-3 per capita in France: indirect (food supply: Ailhaud and Schmidhuber) and direct (dietary food intake $\times$ composition: Inca) methods, and composition of breast milk (Couëdelo et al., 2014). Ailhaud corrected: the change in animal feeding system is take into account; $d$ : trends of apparent daily consumption of n-3 PUFA (g/day) per capita in France: indirect (food supply: Ailhaud and Schmidhuber) and direct (dietary food intake $\times$ composition: Inca) methods, and composition of breast milk (Couëdelo et al., 2014).

and to an increase in the n-6:n-3 PUFA ratio from the 1960s to the late 1990s, followed by a better trend for health of the three FAs. Nevertheless, the values observed in 2014 did not seem to return to those observed in 1960. According to the latest INCA study (2017), deviations from the recommendations are still obvious for SFAs, the n-6:n-3 PUFA ratio and especially the n3 PUFA level.

\subsection{Changes in agri-food systems that changed the fatty acid composition of the French diet}

\subsubsection{Changes related to animal products}

\subsubsection{From the 1960s to the present}

The feeding practices of livestock strongly determine the composition of all animal products (e.g. milk, meat, eggs) (Duru and Magrini, 2016). The content of n-3 PUFAs increases with the proportion of grass in the rations of ruminants and even of monogastrics (pigs and poultry), while cereals reduce the content. In addition, oils in feed concentrates or residual oils in meals can reduce or amplify these effects, depending on their characteristics (Duru and Magrini, 2016). Adding rapeseed oil or meal to animal rations decreases the LA: ALA and n-6:n-3 PUFA ratios of their products compared to adding soybean meal. Adding sunflower (meal or oil) greatly increases the LA:ALA ratio (from 13 to 28) compared to a control ration of soybean meal (Majewska et al., 2016). Marín et al. (2012) demonstrated the influence of the type of oil added to goat diets on the PUFA composition of their milk: the LA: ALA ratio was high (ca. 9) with linoleic sunflower oil, medium (ca. 7.5) with oleic sunflower oil and low (ca. 4) with flaxseed oil. The unbalancing effect of both types of sunflower oil and the balancing effect of flaxseed oil increased with the quantity of oil added (Marín et al., 2012). For pork, Guillevic et al. (2009) demonstrated that replacing sunflower seed with flaxseed in the pig diet increased ALA content in muscle and fat by a factor of ca. 6 and decreased LA content by ca. $20 \%$. Similar results have been reported for cow milk (Glasser et al., 2008), for which adding flaxseed to a maize-based cow diet yielded an ALA content similar to that with a grass diet (Hurtaud et al., 2014).

The quantities of feed concentrates used in France during the studied period increased sharply (Fig. 3): soybean was used in large quantities from the early 1960 s to the late 1990 s, while rapeseed has been used increasingly since the early 2000 s. The increase was slower for sunflower meal.

The changes in feeding practices for ruminants are well documented. From the 1960 s to the 2000 s, feeding switched 


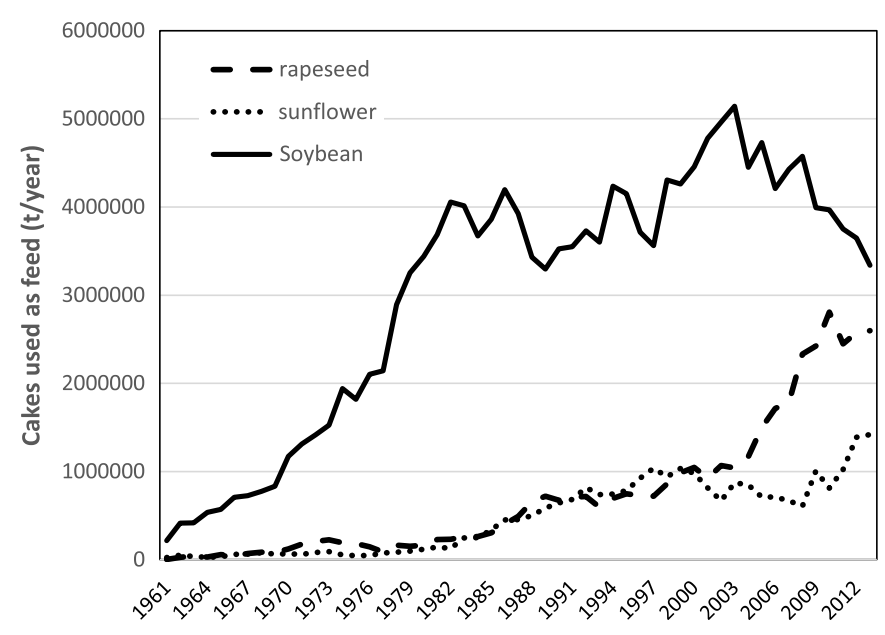

Fig. 3. Cakes used for feeding domestic animals in France (source FAO).

from a grass-based diet to a system dominated by maize silage and soybeans (Tab. 1). Currently, approximately $40 \%$ of milk in France is produced from grass-based rations (Duru and Magrini, 2017), with the remainder produced from rations based mainly on maize and soybeans, the latter decreases the n3 PUFA content in milk and meat. Apparent per-capita consumption of milk, dairy products and meat in France peaked through the early 1990s (Fig. 4). For dairy products, per-capita butter consumption has declined since the beginning of the 1980s, while that of cheese and cream has increased sharply since the early 2000s. Beef consumption plateaued in the early 1980 s (Fig. 4). Taking into account of dairy product consumption and milk fatty content according to change of cow feeding (forage and concentrates) using data of Couvreur et al. (2006), we found that n-3 PUFA intake decreased by $0.10 \mathrm{~g}$ /day from $1961-2000$ and by $0.01 \mathrm{~g}$ /day from $2000-$ present. In contrast, n-6 PUFA intake increased by $0.19 /$ day from 1961-2000 and decreased by $0.04 \mathrm{~g}$ /day from 2000 present. For beef alone, n-3 PUFA intake decreased by $0.01 \mathrm{~g} /$ day, while n-6 PUFA intake increased by $0.07 \mathrm{~g}$ /day from 1961 to present (according to data of van Elswyk and McNeill, 2014), but without considering differences in the type of feed concentrates used.

The change in the FA composition of meat is the most difficult to determine for pigs and poultry because it depends, in part, on breed and selection. For example, selection reduced SFA contents by 7-8 percentage points in pork and chicken (Mourot, 2015). In the 1960s, many pigs and chickens had access to pastures or green waste, which likely yielded products richer in n-3 PUFAs than at present. The increase in sunflower meal in poultry feed has likely increased the n-6 PUFA content in chicken. Pork and poultry consumption increased sharply from 1960-1980 and 2000-present, respectively (data not shown), while beef consumption decreased, which resulted in a diet less balanced in PUFAs since products from monogastrics tend to have a n-6:n-3 PUFA ratio higher than those from ruminants.

In summary, from 1960-2000 for beef and dairy products, changes in animal feed reduced n-3 PUFA intake by at least $0.12 \mathrm{~g} /$ day and increased that of $\mathrm{n}-6$ PUFA by $0.25 \mathrm{~g} / \mathrm{day}$. These values may increase when considering changes in pig and poultry feed. For all animal products, Ailhaud et al. (2006) reported a $72 \%$ decrease in n-3 PUFA contents from 1960 2000 , which is greater than our estimate for ruminant products (i.e. $25-65 \%$ decrease, depending on the assumption). Since 2000, the changes observed during the 1990-2000s have slowed, and the trends may have improved due to the feeding of rapeseed meal, especially for cattle.

\subsubsection{Potential improvements resulting from feeding flaxseed to animals}

In the context of reduced meat consumption, many scenarios have proposed prioritizing grasslands for feeding ruminants. On the other hand, grasslands may remain a niche for pigs and poultry, which are highly criticized for having diets that compete with those of humans for land use (Van Zanten et al., 2018). Flaxseed intake by animals increases the n-3 PUFA content of their products (Fig. 5; Schmitt et al., 2018). Since the n-6 PUFA content decreases slightly, the n-6: n-3 PUFA ratio becomes $<4$ for all animal products (Fig. 5). Currently, BBC products, which guarantee a minimum n-3 PUFA content, represent $10 \%$ of the French production volume of pork, $5 \%$ of eggs, $4 \%$ of poultry, and $<1 \%$ of milk and red meat (N. Kerhoas, BBC association, pers. comm.). For these reasons, we simulated effects of switching to $100 \% \mathrm{BBC}$ products for pork, eggs and poultry, without changing their consumption levels in the diet: the supply of n-6 PUFAs decreased from 2.80 to $2.71 \mathrm{~g} /$ day and that of n-3 PUFAs increased from 0.22 to $1.02 \mathrm{~g} /$ day. This option alone makes it possible to increase intake of n-3 PUFAs by 0.8 /day and decrease that of n-6 PUFA by $0.09 \mathrm{~g} /$ day. In addition to this benefit for health, flax is a minor crop that provides agronomic benefits to cropping systems (Meynard et al., 2018).

\subsubsection{Changes in the oils supplied \\ 3.3.2.1 From the 1960s to the present}

Major changes from 1960-present included the considerable increase in the apparent consumption of oils, from 20 to $>50 \mathrm{~g} /$ day, with sunflower representing up to $50 \%$ at the end of the 1980 s, due mainly to a sharp decrease in consumption of peanut oil. Other relevant changes include the beginning of rapeseed oil consumption in 1980 and its increase in the 1990s, the steady growth in olive oil consumption, the increase in soybean oil consumption in the 1970s and again in the 1990s, and the increase in palm oil consumption, which peaked in the early 1990s (Fig. 6a). These oils are increasingly hidden from consumers. In the early $1960 \mathrm{~s}$, for example, most oils were consumed directly, while in 1980 , the agri-food industries used 38\% (Dilas, 2005).

Apparent consumption of SFAs increased by ca. 35\% from 1960 -present and then plateaued. Since 1985, palm oil consumption decreased from ca. $35 \%$ to $15 \%$ of oils (Fig. $6 \mathrm{~b}$ ). Apparent consumption of LA increased sharply over 50 years (by a factor of 5), due mainly to the increase in apparent consumption of sunflower oil until the late 1980s (Fig. 6c). From the early 2000s, the contribution of sunflower oil was probably even lower than that estimated (Fig. 6c) since some was derived from oleic sunflower, which is less rich in LA. The apparent consumption of ALA from oils increased greatly in the 1960 s due to the consumption of soybean oil, and then in 
Table 1. Changes in silage maize and grassland areas, soybean meal imports and rapeseed meal from 1960 to the present, with qualitative impact assessment of the balance between n-3 and n- 6 polyunsaturated fatty acids (PUFAs). Symbols $(+,=,-)$ indicate trends in area (silage, grassland) or quantity (meals) and their influence on the n-6:n-3 PUFA ratio, respectively.

\begin{tabular}{|c|c|c|c|c|c|c|c|c|c|}
\hline Period & \multicolumn{5}{|c|}{ Silage maize and grass } & \multicolumn{2}{|c|}{ Soybean } & \multicolumn{2}{|c|}{ Rapeseed } \\
\hline 1980-1990 & ++ & -- & - & - & -- & ++ & -- & / & \\
\hline 1990-2000 & $=$ & - & $=$ & $(-)$ & - & + & - & + & $(+)$ \\
\hline
\end{tabular}

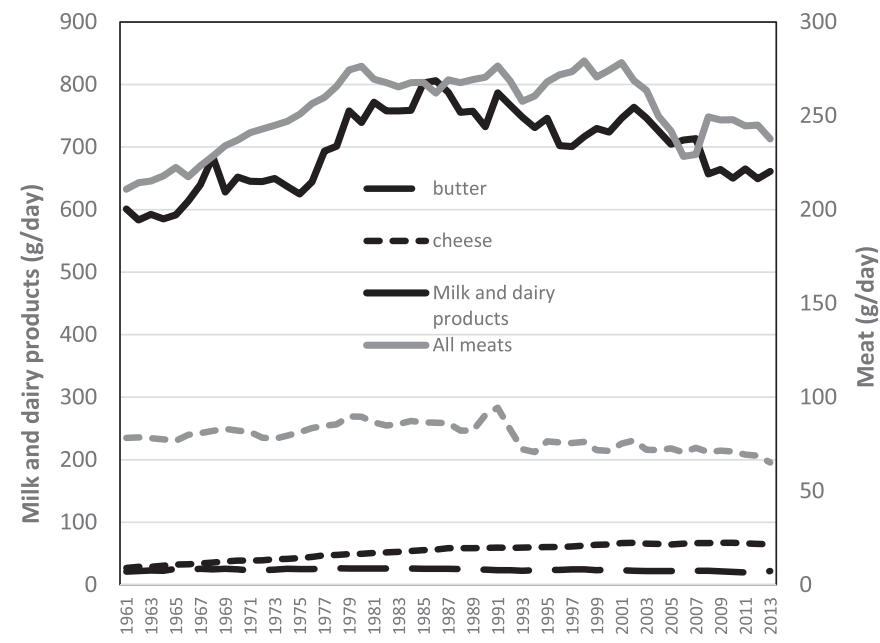

Fig. 4. Trends of apparent meat, milk and dairy products consumption per capita in France (source FAO).

the beginning of the 1980 s due to the consumption of rapeseed oil. These two oils alone have contributed nearly the entire supply of ALA (Fig. 6d).

\subsubsection{Possible improvements by replacing oils}

Beyond reducing oil consumption, especially in industrial food, a major improvement was the replacement of linoleic with oleic sunflower oil, whose FA composition is similar to that of olive oil, as well as replacing soybean oil with rapeseed oil. The percentage of oleic sunflower grown on France's sunflower area increased from $10 \%$ in 2001 to $50-60 \%$ since 2006 (TerreUnivia). Analysis of trade, however, indicates that the quantity imported has equaled a mean of $2 / 3$ of exports since 2006 (Fig. 7). Since France is the largest producer of oleic sunflower in Europe, it is assumed that these imports are almost exclusively linoleic oil. Assuming that $15-25 \%$ of the sunflower oil consumed in France is oleic (Duru and Magrini, 2017) results in the estimate that $66-80 \%$ of this oil is exported. Inverting the consumption percentages to assume that sunflower oil consumption is $25 \%$ linoleic and $75 \%$ oleic does not change ALA intake, but it does reduce apparent LA consumption by $4.5 \mathrm{~g} /$ day $(23 \%)$ and decrease the LA:ALA ratio from 12 to 9 . In addition, replacing half of the soybean oil

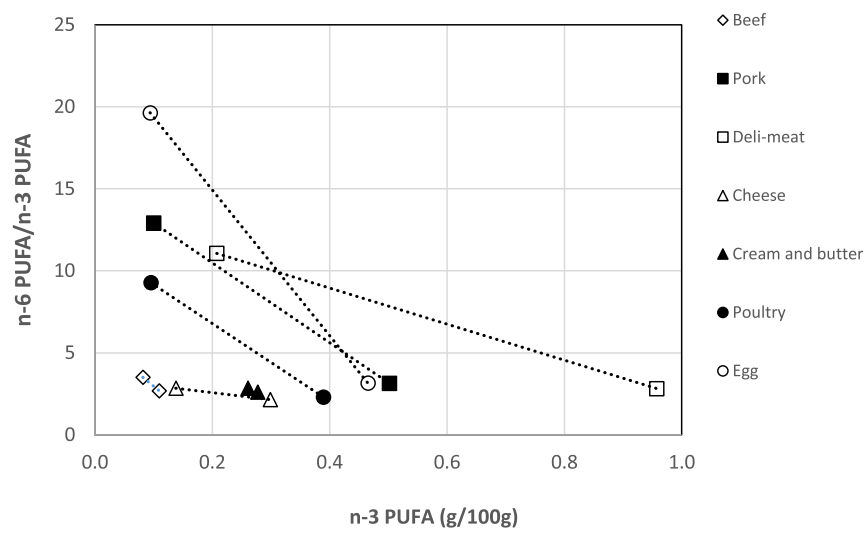

Fig. 5. Relationship between n-6/n-3 PUFA ratio and n-3 PUFA for standard (left side of the line) and improved (with flaxseed addition) products (right side of the line) (from Schmitt et al., 2018).

with rapeseed oil would reduce apparent consumption of LA by $1.6 \mathrm{~g} /$ day (i.e. $31 \%$ lower than at present) and increase ALA intake by $0.2 \mathrm{~g} /$ day (i.e. $12 \%$ higher). Based on these two changes, the LA:ALA ratio decreases by $40 \%$.

\subsection{Whether the combined changes in livestock and oils explain trends and meet FA recommendations in the future}

We compared estimates of the apparent consumption of the FAs calculated over the past 50 years or simulated for the future, to physiological needs and recommended dietary intakes. According to ANSES (2011), the minimum physiological intake of LA and ALA is 2.0 and $0.8 \%$ of energy input, respectively (i.e. 4.0 and $1.6 \mathrm{~g}$ /day for an energy intake of $2000 \mathrm{kcal}$, respectively) (Tab. 2). Recommended nutritional supplies for LA and ALA were 4 and 1\% of the energy supply, i.e. 8.0 and $2.0 \mathrm{~g} / \mathrm{day}$, respectively (Anses, 2011), which corresponds to requirements for adults and adolescents representing $88 \%$ of the French population in 2012. The recommended LA:ALA ratio was set at 5 (Anses, 2011) or even lower (2) (Yang et al., 2016) to prevent certain diseases. Recommendations for docosahexaenoic acid (DHA) and eicosapentaenoic acid (EPA) due to an ALA deficiency in the French diet were set at $250 \mathrm{mg}$ /day for each (Tab. 2). 
(a)

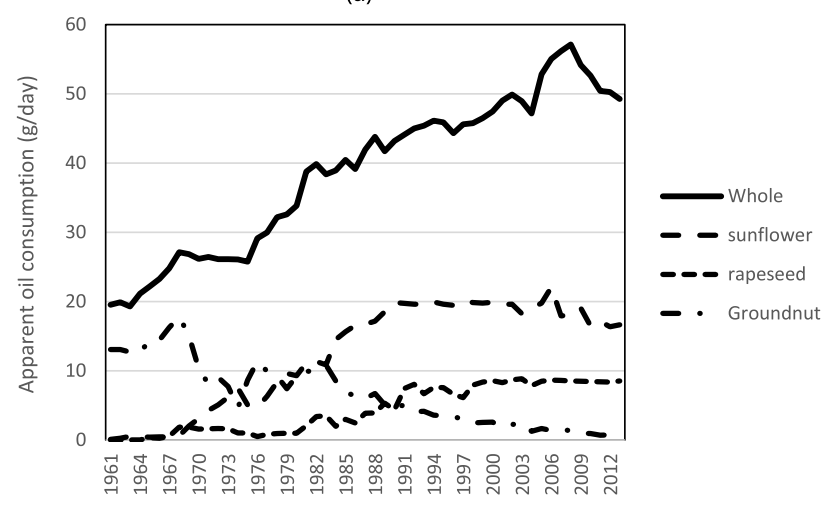

(c)

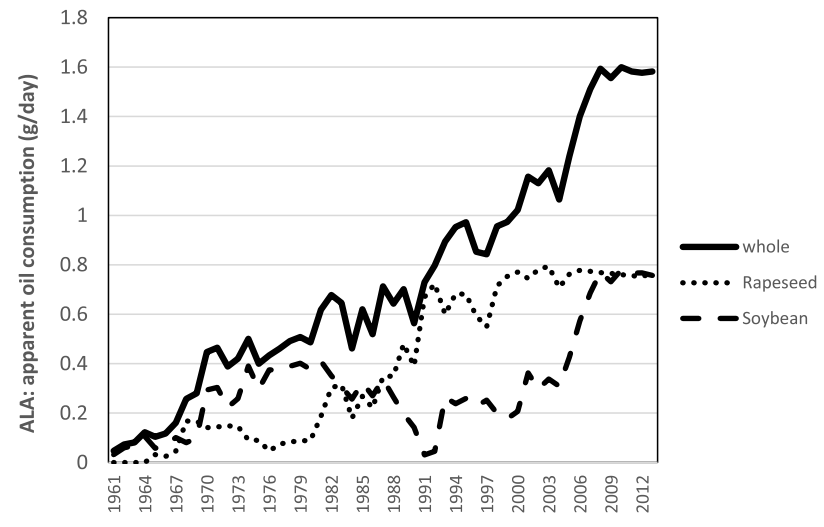

(b)

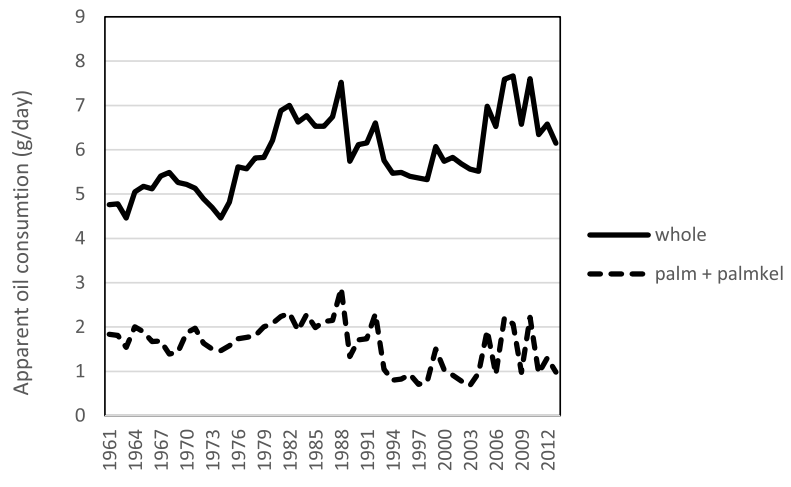

(d)

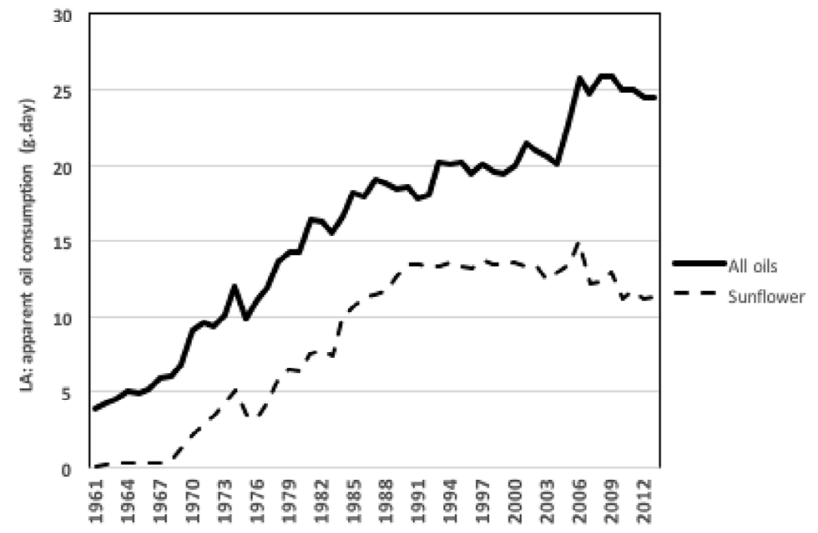

Fig. 6. a: per capita apparent consumption of three oils and total in France (source FAO); b: per capita apparent consumption of saturated fatty acids (SFA) for whole oils and palm oil in France (source FAO); c: per capita apparent consumption of alpha-linolenic fatty acid (ALA) for all oils and sunflower oil in France (source FAO); d: per capita apparent consumption of linoleic fatty acid (LA) for all oils and sunflower oils in France (source FAO).

From 1960-present, cheese and butter were responsible for the increase in the apparent consumption of SFAs, well ahead of palm oil: cheese consumption increased greatly from 1960 (27 g/day) to 2000 (76 g/day) and then plateaued (Fig. 4). Apparent consumption of SFAs via these dairy products increased from 6 to $13 \mathrm{~g}$ /day, while apparent consumption via oils increased from 5.0 to $6.5 \mathrm{~g}$ /day during the same period. Recent literature strongly suggests distinguishing long-chain FAs (palmitic, myristic and lauric acids) from other SFAs because they are atherogenic when in excess (Anses, 2011). Contents of these SFAs are high in palm oil (50\%), low in meat $(<1 \%)$ and intermediate in cheese $(7.5 \%)$, cream $(10 \%)$ and butter $(20 \%)$, and palmitic acid constitutes ca. half of SFAs in dairy products, unlike in palm oil. Consequently, the increase in these SFAs in the diet during the study period was $<1 \mathrm{~g} /$ day for oils (from $0.8 \mathrm{~g}$ /day in 1961 to $1.7 \mathrm{~g} /$ day in 2013 ) and $2.5 \mathrm{~g}$ / day for cheese (i.e. $14 \mathrm{~g} /$ day in 2013). In comparison, the INCA 3 study (2017) estimated intake of $20 \mathrm{~g} /$ day for these three SFAs (i.e. ca. $70 \%$ of the supply), when they should be $<16 \mathrm{~g}$ for an energy supply of $2000 \mathrm{kcal}$ (Anses, 2011). This period also experienced a much faster increase in n-6 PUFA intake than n-3 PUFA intake, which increased deviations from the recommendations. Although fish and shellfish consumption was not considered, their per-capita apparent raw consumption increased from $<40 \mathrm{~kg} /$ year to $>70 \mathrm{~kg} /$ year from 1961-2013 in France ${ }^{3}$, thus contributing to an increase in the n-3 PUFA level in the diet. Fish provided an average of $0.13 \mathrm{~g}$ of LA and $0.05 \mathrm{~g}$ of ALA per day and per capita over the same period.

Since 2000, the gap between supply and recommendations of SFAs, n-6 PUFAs and n-3 PUFAs has decreased. For SFAs, cheese consumption did not increase, while that of butter and palm oil decreased. The decrease in the apparent consumption of n-6 PUFAs is likely related to the lower consumption of linoleic sunflower oil. The increase in the apparent consumption of n-3 PUFAs is likely related to the sharp increase in rapeseed oil consumption and, to a very smaller extent, the increase in that of BBC-labeled monogastric products. The last two changes resulted in a decreased n-6:n-3 PUFA ratio. They also resulted in improvement in the three FA indicators for human health and are consistent with the improvement observed in the FA composition of breast milk (Figs. $2 \mathrm{~b}$ and $2 \mathrm{c}$ ).

We simulated the combination of the two changes mentioned previously (i.e. feeding flaxseed to pigs and poultry, and replacing oils at home and/or in processed products) (Tab. 2). These changes enabled nearly meeting the recommended supply of n-3 PUFAs (overall, without

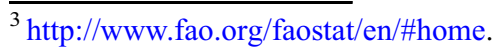


Table 2. Polyunsaturated fatty acid (PUFA) requirements, supplies and simulations for changes in the diet (g/day). Minimum physiological requirements for PUFAs for an adult with a daily energy intake of $2000 \mathrm{kcal}$ (excluding alcohol).

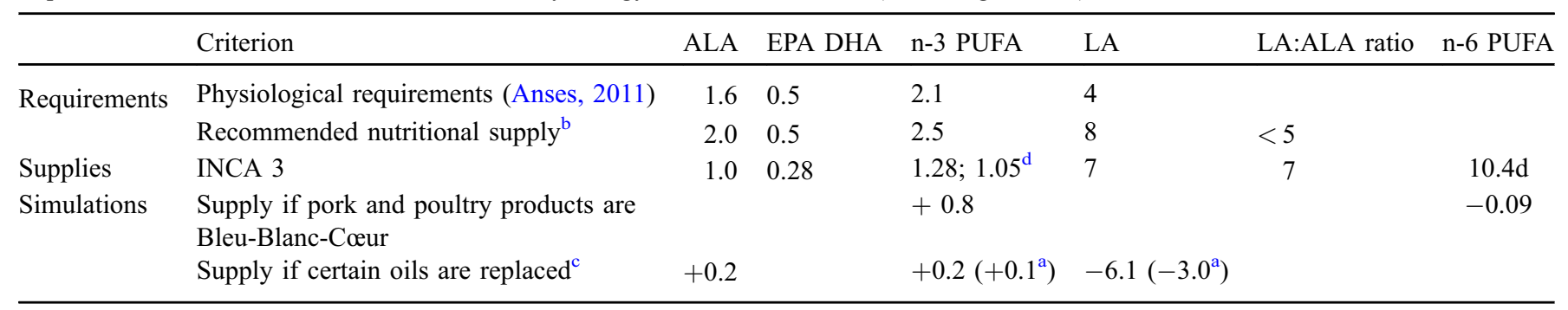

${ }^{\text {a }}$ If $50 \%$ of the oil supply is consumed.

b https://www.Anses.fr/fr/system/files/NUT2012SA0103Ra-2.pdf.

c Rapeseed instead of soybean, oleic sunflower instead of linoleic sunflower.

d Schmitt et al. (2018).

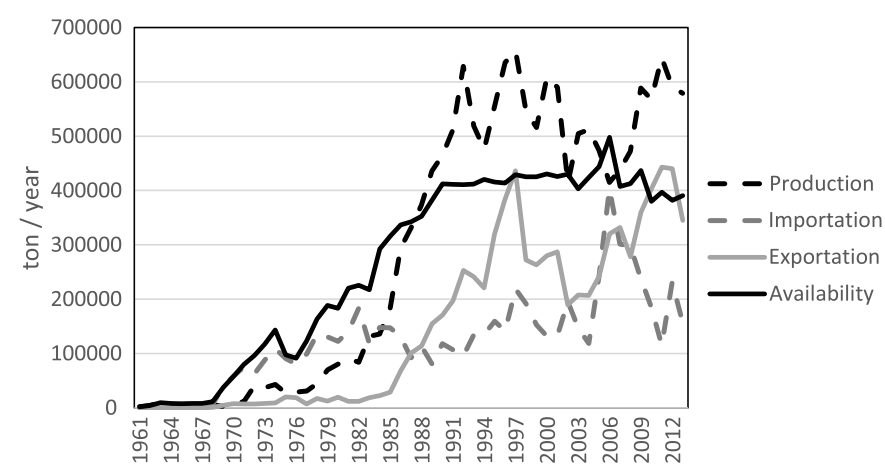

Fig. 7. Production, importation, exportation and supply of sunflower oil in France (source FAO).

distinguishing between DHA and EPA), and even exceeded physiological requirements. $\mathrm{BBC}$ pork products alone explained half of the increase. In contrast, BBC products changed the n-6 PUFA supply only slightly, but replacing oils changed it greatly, depending greatly on the quantity of oil consumed.

\section{Conclusion}

FA intake of the French population since the 1960s was estimated using several methods (dietary composition, raw products supplied) and databases of food composition. Since we found convergent trends, this diversity makes the estimates robust and does not present an obstacle to identifying major drivers of the trends and drawing conclusions.

The FA composition of the average French diet changed most mainly before the $2000 \mathrm{~s}$. This change was related to the increase in SFA intake up to the 1990s, due more to the increase in the quantity of dairy products (especially cheese) consumed $(+1.2 \mathrm{~g} /$ day $)$ than to that of oil $(+2 \mathrm{~g} /$ day $)$. The strong increase in LA intake was due mainly to the increase in the quantities of oils consumed, especially linoleic sunflower oil. At the same time, n-3 PUFA intake increased by $0.5 \mathrm{~g} /$ day from oils and decreased by $0.1 \mathrm{~g} /$ day from animal products. Despite uncertainty in these estimates, in the contribution of animal products to n-3 PUFA intake and in the percentage of non-consumed oils, the n-6:n-3 PUFA ratio has increased from 1960-present. In summary, the two characteristics that have a negative impact on health (SFA level and n-6:n-3 PUFA ratio) increased during this period, which highlights deviations from the recommendations. These deviations, which peaked in the late 1990 s, were a risk factor for development of chronic noncommunicable diseases, since they were concomitant. Note that changes in the consumption of FAs are a component of the nutrition transition (Maire et al., 2002).

Improvements occurred from the years around 2000 up to 2013, due mainly to stabilization of the FA composition of animal products in the absence of notable changes in animal rations (roughage, cereals). It was also likely due to improvements resulting from introduction of rapeseed meal and oil or flaxseed in rations. While total oil consumption plateaued or decreased by the end of the studied period, improvements also resulted from increased rapeseed oil consumption and decreased sunflower oil consumption, as well as replacement of some linoleic sunflower oil with oleic sunflower oil, which contains much less LA. These changes resulted in decreased SFA and n-6 PUFA intake, and increased n-3 PUFA intake, which decreased the n-6:n-3 PUFA ratio during this period, a result that is supported by the FA composition observed in breast milk. This period can be defined as the beginning of another nutrition transition: consumption of animal protein decreased while that of more processed products, including processed meats, increased sharply (Laisney, 2012). On one hand, the multiple changes observed for animal products and oils over this period are expected to have positive health effects, since a diet with fewer animal products is likely to have FA and oil compositions that are better for health. However, if these changes are concomitant with greater consumption of ultra-processed products, negative health effects can be expected (Srour et al., 2019). Finally, despite these improvements, estimates of apparent consumption of FAs, even those based on surveys (more accurate than indirect estimates), still lie far from the recommended dietary intakes, particularly for the n-3 PUFA level and n-6:n-3 PUFA ratio.

Our study revealed several mechanisms that can generate improvements in the profile of FA consumption that meet the recommended nutritional supply. For animal products, 
supplementing the rations of pig and poultry with flaxseed appears to be a powerful mechanism, even a necessary condition, for switching from products whose FA composition make them less favorable for health to products that are more favorable. This practice should be considered for these animal species, whose rations strongly compete with human diets for land use. For oils, the issues are simpler because potential replacements exist for several types of oils; however, the objective is to reduce their consumption. The changes required to meet the recommendations thus require the coordination of agricultural policies (animal feeding practices), food processing (types of oils in processed products) and health policies to encourage consumers and stakeholders of collective action to promote the appropriate dietary changes.

\section{Abbreviations}

\section{ALA Alpha-linolenic acid \\ LA Linoleic acid \\ FA Fatty acid \\ SFA Saturated fatty acid}

n-6 PUFA Polyunsaturated fatty acids that have a final carbon-carbon double bond in the $n-6$ position in common

n-3 PUFA Polyunsaturated fatty acids that have a final carbon-carbon double bond in the $n-3$ position in common

Acknowledgments. This research was supported by the PSDR 4 Program (Project ATA-RI; 2016-2020) funded by INRA and the Occitanie Region.

\section{References}

Ailhaud G, Massiera F, Weill P, Legrand P, Alessandri JM, Guesnet P. 2006. Temporal changes in dietary fats: Role of n-6 polyunsaturated fatty acids in excessive adipose tissue development and relationship to obesity. Progr Lipid Res 45: 203-236.

Alcock J, Lin HC. 2015. Fatty acids from diet and microbiota regulate energy metabolism. F1000Research 4: 1-10.

Anses. 2011. Actualisation des apports nutritionnels conseillés pour les acides gras. Rapport d'expertise collective. Disponible sur https://www.anses.fr/fr.

Barendse W. 2014. Should animal fats be back on the table? A critical review of the human health effects of animal fat. Animal Prod Sci 54(7): 831-855.

Blasbalg TL, Hibbeln JR, Ramsden CE, Majchrzak SF, Rawlings RR. 2011. Changes in consumption of omega- 3 and omega- 6 fatty acids in the United States during the 20th century. Am J Clin Nutr 93(5): 950-962.

Casas RS. 2014. The immune protective effect of the mediterranean diet against chronic low-grade inflammatory diseases. Endocr Metab Immune Disord Drug Targets 14(4): 245-254.

Ciqual. 2013. Disponible sur https://www.data.gouv.fr/../table-ciqualde-composition-nutritionnelle-des-aliments-f.

Couëdelo L, Billeaud C, Lamireau D, Perez P, Rigourd V, Buffin R. 2014. Evolution of essential fatty acid composition of French breast milk from 1997 to 2014. EFL Montpellier (poster).

Couvreur S, Hurtaud C, Lopez C, Delaby L, Peyraud JL. 2006. The linear relationship between the proportion of fresh grass in the cow diet, milk fatty acid composition, and butter properties. J Dairy Sci 89: 1956-1969.

Del Chierico F, Vernocchi P, Dallapiccola B, Putignani L. 2014. Mediterranean diet and health: Food effects on gut microbiota and disease control. Int J Mol Sci 15(7): 11678-11699.

Dilas G. 2005. Évolutions du marche français des huiles alimentaires. OCL 12(5-6): 389-392.

Duru M, Magrini M. 2016. Quel potentiel de la prairie pour équilibrer notre alimentation en acides gras? Fourrages 228: 301-312.

Duru M, Magrini M-B. 2017. Composition en acides gras polyinsaturés de notre assiette et utilisation des matières premières agricoles en France: une amélioration lente, mais insuffisante. OCL 24(2): A201.

Georgiadi A, Kersten S. 2012. Mechanisms of gene regulation by fatty acids. Adv Nutr 3(2): 127-134.

Glasser F, Ferlay A, Chilliard Y. 2008. Oilseed lipid supplements and fatty acid composition of cow milk: A meta-analysis. $J$ Dairy $S c i$ 91(12): 4687-703.

Guesnet P, Combe N, Ailhaud G, Alessandri LM. 2009. La teneur en acides gras polyinsaturés du lait maternel: un marqueur biologique fiable du niveau de consommation des populations. OCL 16(1): 1-3.

Guillevic M, Kouba M, Mourot J. 2009. Effect of a linseed diet or a sunflower diet on performances, fatty acid composition, lipogenic enzyme activities and stearoyl-CoA-desaturase activity in the pig. Livest Sci 124(1-3): 288-294.

Hammad S, Pu S, Jones PJ. 2015. Current evidence supporting the link between dietary fatty acids and cardiovascular disease. Lipids 51(5): 507-517.

Hurtaud C, Dutreuil M, Coppa M, Agabriel C, Martin B. 2014. Characterization of milk from feeding systems based on herbage or corn silage with or without flaxseed and authentication through fatty acid profile. Dairy Sci Technol 94(2): 103-123.

Kouba M, Mourot J. 2011. A review of nutritional effects on fat composition of animal products with special emphasis on $n-3$ polyunsaturated fatty acids. Biochimie 93(1): 13-7.

Laisney C. 2012. L'évolution de l'alimentation en France. Document de travail du Centre d'études et de prospective du ministère de l'Agriculture.

Legrand P. 2013. Nouvelle approche pour les recommandations nutritionnelles en lipides. OCL 20(2): 75-78.

Maire B, Lioret S, Gartner A, Delpeuch F. 2002. Transition nutritionnelle et maladies chroniques non transmissibles liées à l'alimentation dans les pays en développement. Cahiers d'études et de recherches francophones/Santé 12(1): 45-55.

Majewska MP, Pająk JJ, Skomiał J, Kowalik B. 2016. The effect of different forms of sunflower products in diets for lambs and storage time on meat quality. Anim Feed Sci Technol. DOI: 10.1016/j.anifeedsci.2016.10.007.

Marín AM, Gómez-Cortés P, Castro GG, et al. 2012. Effects of feeding increasing dietary levels of high oleic or regular sunflower or linseed oil on fatty acid profile of goat milk. J Dairy Sci 95(4): 1942-1955.

Meynard JM, Charrier F, Le Bail M, Magrini MB, Charlier A, Messéan A. 2018. Socio-technical lock-in hinders crop diversification in France. Agron Sustain Dev 38(5): 54.

Molendi-Coste O, Legry V, Leclercq IA. 2011. Why and how meet n3 PUFA dietary recommendations? Gastroenterol Res Pract 2011: 1-11. Article ID 364040. DOI: 10.1155/2011/364040.

Mourot J. 2015. Évolution de la qualité des produits animaux ces cinquante dernières années. Cah Nutr Diet 50: 1-6.

Pereira de Castro A, Aiko Hiane P, de Cássia Avellaneda Guimarães $\mathrm{R}$, et al. 2017. Fatty acids consumption: The role metabolic 
aspects involved in obesity and its associated disorders. Nutrients 9: 1158. DOI: 10.3390/nu9101158.

Pisani DF, Amri E-Z, Ailhaud G. 2015. Disequilibrium of polyunsaturated fatty acids status and its dual effect in modulating adipose tissue development and functions. OCL 22(4): D405.

Rocha DM, Caldas AP, Oliveira LL, Bressan J, Hermsdorff HH. 2016. Saturated fatty acids trigger TLR4-mediated inflammatory response. Atherosclerosis 244: 211-215.

Sanders TAB. 2014. Protective effects of dietary PUFA against chronic disease: Evidence from epidemiological studies and intervention trials. Proc Nutr Soc 73(1): 73-79.

Sanz Y, Olivares M, Moya-Pérez Á, Agostoni C. 2015. Understanding the role of gut microbiome in metabolic disease risk. Pediatr Res 77(1): 236-244.

Schmidhuber J. 2007. The EU diet-evolution, evaluation and impacts of the CAP. WHO Forum on "Trade and healthy food and diets", Montreal, Canada.

Schmitt B, Ferry C, Mairesse G, et al. 2018. The choice of animal feeding system influences fatty acid intakes of the average French diet. OCL 25(2): D205.

Simopoulos AP. 2007. Evolutionary aspects of diet, the omega-6/ omega-3 rapport and genetic variation: Nutritional implications for chronic diseases. Biomed Pharmacother 60: 502-507.
Simopoulos AP. 2016. An increase in the Omega-6/Omega-3 fatty acid ratio increases the risk for obesity. Nutrients 8(3): 1-17.

Silva Figueiredo P, Carla Inada A, Marcelino G, et al. 2017. Fatty acids consumption: The role metabolic aspects involved in obesity and its associated disorders. Nutrients 9(10): 1158.

Srour B, Fezeu LK, Kesse-Guyot E, et al. 2019. Ultra-processed food intake and risk of cardiovascular disease: Prospective cohort study (NutriNet-Santé). BMJ 11451. DOI: 10.1136/bmj. 11451.

van Elswyk ME, McNeill SH. 2014. Impact of grass/forage feeding versus grain finishing on beef nutrients and sensory quality: The U.S. experience. Meat Sci 96: 535-540.

Van Zanten HHE, Herrero M, Van Hal O, et al. 2018. Defining a land boundary for sustainable livestock consumption. Glob Chang Biol (December): 1-10. DOI: 10.1111/gcb.14321.

Yang LG, Song ZX, Yin H, Wang YY, Shu GF, Lu HX. 2016. Low n6/n-3 PUFA rapport improves lipid metabolism, inflammation, oxidative stress and endothelial function in rats using plant oils as n-3 fatty acid source. Lipids 51: 49-59.

Xiang MS, Tan JK, Macia L. 2019. Fatty acids, gut bacteria, and immune cell function. In: The molecular nutrition of fats. Academic Press, pp. 151-164. DOI: 10.1016/B978-0-12-8112977.00011-1.

Cite this article as: Duru M. 2019. Trends in agri-food choices for health since the 1960s: the case of fatty acids. OCL $26: 44$. 